\title{
Projeto Arte na Escola: formação e mediação
}

\author{
Projeto Arte na Escola: formación y mediación \\ Projeto Arte na Escola: formation and mediation
}

\author{
Carmem Regina Silveira Nogueira ${ }^{1}$ \\ Nádia da Cruz Senna ${ }^{2}$
}

\begin{abstract}
Resumo
O Projeto Arte na Escola - Polo UFPel integra uma rede nacional com a missão de promover a formação continuada para o professor de artes que atua nas diferentes etapas do ensino, visando qualificar processos de aprendizagem com intenção de formar cidadãos mais perceptivos, criativos e críticos de sua realidade. Nosso compromisso compreende a formação em escala ampliada e inclusiva, o que implica em promover ações de formação para o público da região geoeducacional de Pelotas. Em nossa concepção arte é uma área de conhecimento, objeto do saber, fazer, perceber, refletir, criar, criticar, ou seja, opera com todas as dimensões da produção da obra de arte. Para dar conta dessas metas o projeto promove oficinas, cursos, mostras, jornadas de aprimoramento, encontros e ciclos de debates e seminários, que contemplam a diversidade das linguagens artísticas, bem como dimensões poéticas e educacionais. A linha metodológica é integradora, multidisciplinar e aberta às motivações e demandas dos grupos participantes, segundo concepções emergentes que percebem o processo artístico como experiência dinâmica, cognitiva, simbólica e coletiva.
\end{abstract}

Palabras chaves: arte-educação; formação e mediação

\section{Resumen}

El Projeto Arte na Escola - Polo UFPel integra una red nacional con la misión de promover la formación continuada para el profesor de artes que actúa en las diferentes etapas de la enseñanza, buscando calificar procesos de aprendizaje con la intención de formar ciudadanos más perceptivos, creativos y críticos de su realidad. Nuestro compromiso comprende la formación en escala expandida y inclusiva, promoviendo acciones de formación para un público mayor en la región de Pelotas. En nuestra concepción arte es un área de conocimiento, objeto del saber, hacer, percibir, reflejar, crear, criticar, o sea, opera con todas las dimensiones de la producción de la obra de arte. Para dar cuenta de esa meta el proyecto promueve talleres, cursos, muestras, jornadas de perfeccionamiento, encuentros y ciclos de debates y seminarios, que contemplan la diversidad de lenguajes artísticos, así como dimensiones poéticas y educativas. La línea metodológica es integradora, multidisciplinaria y abierta a las motivaciones y demandas de los grupos participantes, siguen concepciones emergentes que perciben el proceso artístico como experiencia dinámica, cognitiva, simbólica y colectiva.

Palabras claves: educación artística; formación y mediación

\begin{abstract}
The Projeto Arte na Escola - Polo UFPel integrates a national network with the mission of promoting continuing education for the arts teacher who works in the different stages of teaching, aiming to qualify learning processes with the intention of forming more perceptive, creative and critical citizens of your reality. Our commitment involves education in expanded and inclusive scale, which implies promoting education actions for the public in the Pelotas region. In our conception art is an area of knowledge, an object of knowledge, to make, to perceive, to reflect, to create, to criticize, that is, to operate with all dimensions of the production of the work of art. In order to fulfill this goal, the project promotes workshops, courses, shows, improvement, meetings and cycles of debates and seminars, aiming to contemplate the diversity of artistic languages, as well as poetic dimensions and

1 Doutoranda em Artes y Humanidades (UNR, Argentina); Centro de Artes, Universidade Federal de Pelotas, Pelotas, RS, Brasil; carmemnogueira@gmail.com

2 Doutora em Ciências da Comunicação (USP, Brasil); Centro de Artes, Universidade Federal de Pelotas, Pelotas, RS, Brasil; alecrins@ @otmail.com
\end{abstract}


the teaching of art. The methodological line is integrative, multidisciplinary and open to the motivations and demands of the participating groups follow emerging conceptions that perceive the artistic process as dynamic, cognitive, symbolic and collective experience.

Keywords: art education; formation and mediation

\section{Introdução}

O Projeto Arte na Escola vinculado ao Centro de Artes da Universidade Federal de Pelotas/UFPel teve seu início em 1995, a partir de um convênio feito entre a Universidade e o Instituto Arte na Escola. O projeto tem o compromisso de promover a formação continuada para o professor de artes que atua em diferentes etapas de formação, com intenção de qualificar processos de aprendizagem. Atualmente, existem 50 Polos que integram a rede nacional, unidos por um ideal - melhorar o ensino da arte no país. A Rede Arte na Escola reúne universidades, instituições culturais e educacionais, que qualificam professores dos níveis infantil, fundamental e médio e os estimulam a formar jovens mais perceptivos, criativos e críticos de sua realidade.

O Polo se instala na cidade de Pelotas, pela sua condição de centro de formação da região sul, o que implica estender as ações para um público maior e contemplar a formação continuada, a formação dos futuros professores de arte e formação da comunidade de modo geral. O Projeto se estabelece como ação extensionista, articulada com o ensino e a pesquisa, executando atividades diferenciadas para alcançar os objetivos traçados.

Em nossa concepção a arte é assumida como área de conhecimento, como objeto do saber, fazer, perceber, refletir, criar, criticar, ou seja, opera com todas as dimensões da produção da obra de arte até alcançar sua circulação. O projeto, que inicialmente era voltado para as demandas do ensino das artes visuais, hoje contempla a diversidade de linguagens artísticas, o hibridismo dos processos poéticos e educativos, na perspectiva da arte contemporânea.

As ações de formação continuada são voltadas para os professores da rede escolar, oportunizando qualificação também aos futuros professores como formação complementar que é devidamente reconhecida pelos Projetos Políticos Pedagógicos dos cursos do Centro de Artes. A linha metodológica é integradora, multidisciplinar e aberta às motivações e demandas dos grupos participantes, seguem concepções emergentes que percebem o processo artístico como experiência dinâmica, cognitiva, simbólica e coletiva. Compreendemos que os processos desencadeados pela arte contemporânea perpassam questões relacionadas à ética, 
identidade, memória, cultura e pertencimento proporcionando conhecimento de si e de mundo.

O projeto aglutina grupos interessados nessa formação plural e crítica, para tanto disponibilizamos as instalações, a estrutura pedagógica e acadêmica do Centro de Artes e o acervo, propriamente dito, do Projeto Arte na Escola. As ações se caracterizam pelo empréstimo de livros e materiais pedagógicos, promoção de oficinas, cursos, mostras didáticas, apresentações artísticas, seminários e encontros entre grupos de trabalho, alcançando o fazer artístico, sua fruição e reflexão

Nesse artigo selecionamos alguns dos projetos já executados com intenção de dar visibilidade a diversidade de atividades empreendidas, organizadas como Ações na Escola e Qualificação Acadêmica.

\section{Ações na Escola}

A atuação integrada com a escola prepondera sobre as demais atividades desenvolvidas pelo Projeto, pela natureza das ações de formação continuada, formação complementar, de apoio ao ensino da arte e proposição de práticas que envolvem a escola e a universidade. A gestão atual investiu em estratégias de aproximação com a escola, por constatar as dificuldades do professor da rede em acompanhar o Projeto Arte na Escola, mesmo com o apoio do site (https://wp.ufpel.edu.br/artenaescola/) que divulga as ações e o acervo.

Nesse viés visitamos as escolas e estabelecemos parcerias voltadas a atender demandas específicas, junto ao professor de arte e suas turmas, durante o ano letivo. Há um planejamento que contempla todas as etapas necessárias para a realização das atividades, bem como reuniões para ajustes e avaliação ao longo do processo. O trabalho é pensado e realizado em grupo e se desenvolve no próprio espaço da escola, dessa forma experimentamos ações educativas que articulam a arte com as temáticas sugeridas ou com o programa de necessidades levantado, tais como: arte e natureza, arte para portadores de necessidades especiais, poesia e letramento, arte e cultura popular, arte e moda, arte e gênero, entre outros.

As demandas das escolas e espaços comunitários voltados para alunos com necessidades especiais exigem que repensemos nossa formação, revendo projetos pedagógicos, que muitas vezes não contemplam conteúdos ou fornecem competências para que atuemos com esses grupos. Nos referenciamos em arte-educadores que são autoridades reconhecidas pelas inovações e experimentações que desenvolvem, e com os quais 
estabelecemos diálogos e parcerias para dar conta das proposições: Ana Mae Barbosa, Miriam Celeste Martins, Raimundo Martins, Irene Tourinho, Francisco Duarte Jr., Rosa Iavelberg, Guacira Louro, entre outros e outras.

A proposta desenvolvida junto a Escola Especial Alfredo Dub (Figura 1), que atende crianças com dificuldades auditivas, implicou em trabalho coletivo e intercâmbio de saberes, exigindo a instrumentalização dos licenciados em artes visuais na linguagem dos sinais, a equipe desenvolveu materiais pedagógicos centrados na visualidade para facilitar a compreensão das propostas e o aprendizado das técnicas de desenho.

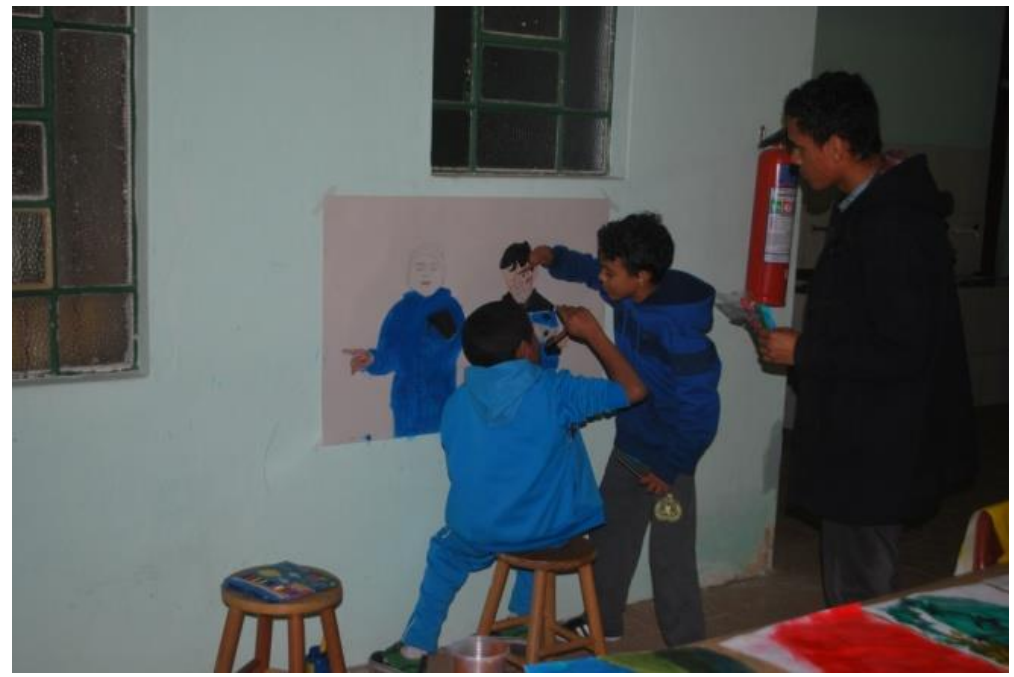

Figura 1 - Exercício de autorretrato com alunos da Escola Alfredo Dub, 2015. Fonte: Autoras

A ação priorizou o ensino de desenho, explorando a gestualidade da mão, como forma e expressão de comunicação. Propomos exercícios com sombras projetadas, criação de figuras fantásticas a partir de carimbos, desenhos de linha contínua, desenhos de observação de posturas e expressões fisionômicas em produções coletivas e individuais, com diferentes técnicas e materiais em tamanhos ampliados. A experiência exitosa com a turma de alunos selecionada, ganhou a adesão dos demais alunos, nos levando a ampliar o cronograma e as equipes de trabalho para atender o interesse. $\mathrm{O}$ feito culminou com a produção de retratos e autorretratos envolvendo a comunidade por inteiro, resultando em uma exposição "Alfredo Dub mostra a tua cara" que integrou as atividades do aniversário da escola.

Para o grupo de alunos da Escola Louis Braille, que atende portadores com deficiências visuais, oferecemos duas oficinas, uma centrada na música, ministrada pelo professor de flauta transversa do Centro de Artes e licenciandos do curso de música e, outra explorando sentidos e sensações, com licenciandos de artes visuais, que ocorreu junto ao ateliê de cerâmica do Centro de Artes. 
A experiência é fundamentada no saber sensível (Duarte Jr., 2004), conhecimento primitivo e fundador que adquirimos através dos sentidos do corpo. A oficina de musicalização deu ênfase aos jogos e improvisações a partir da percussão corporal provocando o grupo a criar sons e ritmos com palmas, estalos, sapateados e recursos vocais. $\mathrm{O}$ ateliê de cerâmica despertou muita curiosidade, o espaço era desconhecido e ainda, agregava cheiros e materiais que convidavam o grupo a experimentação. Reunimos objetos, frutas e flores, ricos em cheiros, texturas e volumetrias, o grupo se lançou na exploração sensível, descrevendo sensações e estabelecendo relações funcionais e fantasiosas, fazendo aflorar memórias e emoções em todos nós. Pura estesia (Figura 2).

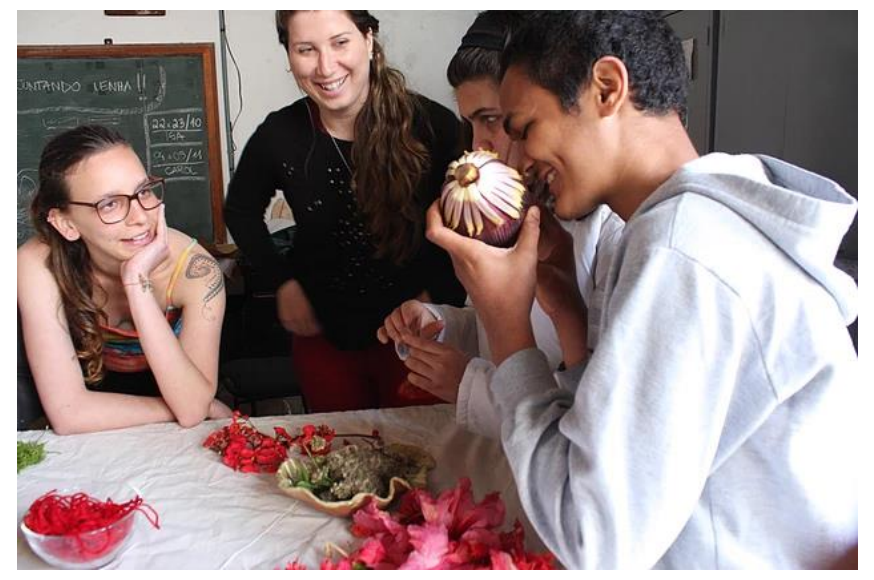

Figura 2 - Explorando sentidos e sensações, 2016. Fonte: Autoras.

Essas experiências nos fizeram atentar para a necessidade de formar arte-educadores capazes de ativar os mecanismos sensíveis de que somos dotados, para que reaprendamos a desvelar o mundo pela poesia, "o que em mim sente, está pensando" (Fernando Pessoa). Os sentidos do corpo, a gestualidade e a ludicidade constituíram temas fundamentais para os grupos de estudo, experimentamos as estratégias desenvolvidas em outras escolas, com turmas de diferentes idades, buscando sensibilizá-los para as diferenças. Montamos "salas sensíveis" e convidamos os participantes a desembotarem seus sentidos, nos referenciamos na arte contemporânea, enfatizando produções e artistas propositivos. Os processos vivenciados instauraram novas investigações constituindo trabalhos de conclusão de cursos e dissertações de mestrado, confirmando a relação indissociada que caracteriza a nossa atuação e efetivando a qualificação almejada pelo Projeto.

O interesse dos alunos pelas narrativas fantásticas, pelos personagens da cultura visual e pelas manifestações artísticas populares desencadeia oficinas e minicursos que contemplam fazeres, fruições e trocas afetivas. Tal variedade nos fez estabelecer parcerias com grupos de 
pesquisa e projetos de extensão existentes no Centro de Artes, como o Núcleo de Folclore, por exemplo, que tem nos motivado a resgatar brincadeiras, inventar jogos e acionar encontros entre diferentes comunidades e gerações. A oficina de Trajes Folclóricos disponibiliza uma mala com tecidos, roupas e acessórios, que aciona um portal para adentrar no universo encantado do faz de conta, para inventar histórias, vivenciar personagens e ativar memórias. É uma experiência lúdica que ganha desdobramentos poéticos em função dos repertórios artísticos (Figura 3).

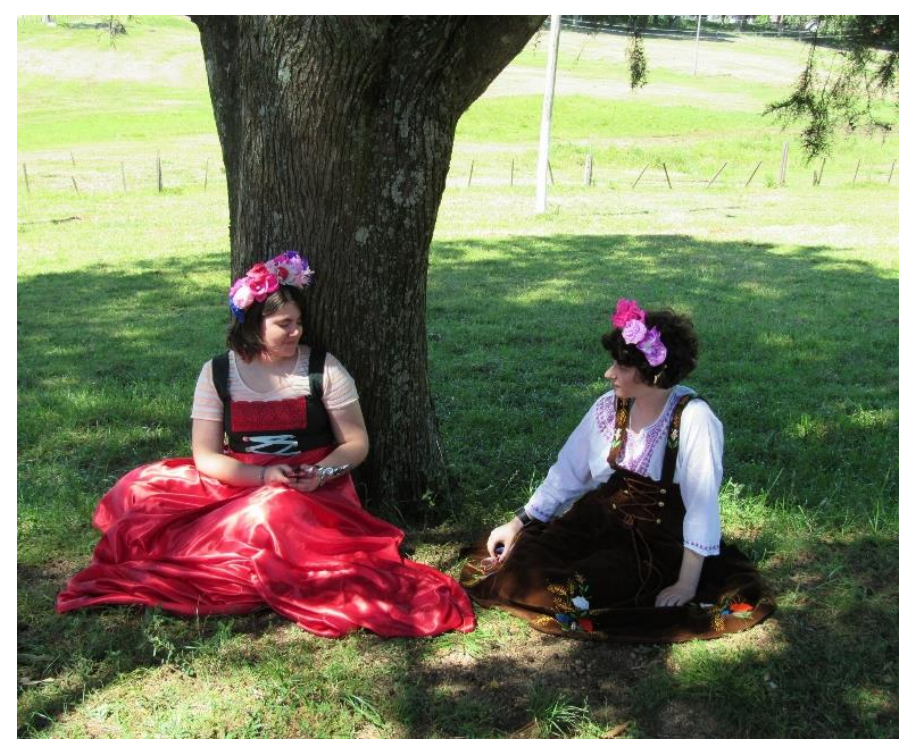

Figura 3 - Oficina de trajes folclóricos, Piratini, 2017. Fonte: Autoras.

\section{Qualificação Acadêmica}

O compromisso com a capacitação dos professores é uma meta inicial que avança em exigências à medida que se consolidam os cursos de pós-graduação na área de artes. Essa conjuntura aliada a necessidade de qualificação nos fez investir nessa linha de ação. O Projeto Arte na Escola em seu planejamento anual, prevê a instauração de grupos de estudo e de pesquisa com foco no ensino das artes, processos e poéticas. Tal posicionamento demandou mudanças, inclusive, na forma do cadastro junto a Instituição. O Projeto se estrutura como projeto unificado, uma vez que contempla diferentes instâncias de atuação, produção e reflexão.

Para dar conta da nova dinâmica filiamos ao Projeto o grupo sob nossa coordenação, Caixa de Pandora: estudos em arte, gênero e memória, que reúne os interessados nessa temática, em diferentes níveis de formação, na área de artes e de humanidades. A estratégia se revelou acertada, por conta da articulação que promoveu entre pesquisadores, profissionais, graduandos e pós-graduandos. O grupo instaura um espaço de investigação e reflexão que 
motiva debates e produções proporcionando trocas e partilhas: de autores e leituras, dificuldades e estratégias, metodologias de pesquisa, experiências de sala de aula, de ateliê e de vida. Através dos projetos individuais e coletivos temos contemplado questões sobre arte e gênero, que tanto têm impactado o ensino, a produção e o sistema da arte e da cultura, em nosso país e no mundo, nos últimos anos.

Em nossos encontros orientamos e contribuimos uns com os outros, incentivamos desdobramentos, a redação de artigos e a participação em eventos científicos e artísticos para divulgação dos resultados alcançados; procedemos a organização das produções em mídia eletrônica para uso didático em sala de aula. Promovemos seminários, exposições, palestras e ciclos de debates para apresentar as pesquisas, compartilhar descobertas e inquietações, aproximando a comunidade da linha de estudos de gênero.

A metodologia adotada é de natureza aberta e qualitativa, de forma a comportar acasos, desejos e demais necessidades que se estabelecem, em função do próprio tema da investigação e do interesse por narrativas e visualidades. De modo geral seguimos percursos própios da pesquisa científica, realizamos levantamento bibliográfico, leitura e discussão dos conceitos nos referenciais selecionados, coleta de material em fontes diversas e, principalmente, em nosso acervo da Biblioteca e Midiateca Arte na Escola, formado pelos livros, catálogos, periódicos, materiais didáticos, banco de monografias e dissertações. Conforme interesse do grupo se dá a seleção do material, fichamento e sistematização do conjunto levantado segundo linhas de tempo e temáticas; organização de banco de textos e de imagens; a pesquisa é ampliada junto ao grupo ou de forma individual. Nessa etapa comparecem outros métodos e técnicas conforme desdobramentos artísticos, bibliográficos ou documentais adotados.

As pesquisas sobre protagonismos femininos na arte, filosofia e educação são preponderantes atentando para o interesse das mulheres que integram o grupo que, assim como as demais pesquisadoras, buscam ultrapassar os apagamentos e silenciamentos que a história hegemônica insiste em manter, apesar do ativismo, das transgressões poéticas e reflexivas que questionam cânones e padrões.

Para fundamentar as investigações privilegiamos as mulheres autoras, afinadas com as correntes fenomenológicas, pós-estruturalistas, dos estudos culturais, feminismo e teorias de gênero. Elegemos a noção de representação e performatividade ligada à linguagem e às relações de poder de Foucault e Judith Butler; a interlocução entre público e privado, Eu e o Outro, experiência e condição das mulheres em Simone de Beauvoir, Joan Scott e Luce Irigaray; representantes e representações do feminino na arte em Linda Nochlin, Whitney 
Chadwick, Grizelda Pollock, Ana Paula Simioni entre outras; e a questão do esquecimento ou apagamento das mulheres na história com Michele Perrot e Pierre Bourdieu.

Por conta de nossa atuação junto à área de artes visuais, as mulheres artistas têm presença de destaque nas produções desenvolvidas. Artemísia Gentileschi, Tarsila do Amaral, Frida Kahlo, Maria Martins, Regina Silveira, Judy Chicago, Lígia Clark e Adriana Varejão, são algumas, entre tantas outras, que revisitamos frequentemente por seus méritos e realizações na arte e na cultura.

Recontamos suas histórias em outros formatos e narrativas, experimentamos processos criativos, materiais e técnicas para perceber modos de ver e representar que nos põem em relação com o que realmente sentimos, por afinidade e reflexividade, sobrepujando tempos e distâncias. Michelle Perrot lembra para em nossas investigações "não abandonar a ideia do poder, da influência das mulheres sobre a imagem, pela maneira como a usam, pelo peso de seu próprio olhar" (PERROT, 2017,p.25)

Frida Kahlo e Tarsila do Amaral são fenômenos artísticos, de suas imagens emana um empoderamento que fortalece nossa identidade e nos anima a lutar por nossos direitos. As artistas são lembradas pelo protagonismo exercido, seja pelas inovações artísticas, seja pela postura extraordinária, como mulheres engajadas e vanguardistas. Foram homenageadas na recriação de Dinner Party, de Judy Chicago, uma ceia, realizada na abertura do V Simpósio Internacional de Gênero, Arte e Memória, onde degustamos os pratos que preparamos para essas mulheres que admiramos e que são referências de comportamento, poesia, conhecimento e estilo. São ícones do feminino que sempre comparecem nas pesquisas e oficinas que promovemos, já viraram ilustração (Figura 4) bonecas de papel e de pano, estão nas bolsas e nos bottons, conforme a pesquisa de Manuella Mathias, bolsista do Projeto Arte na Escola, em seu trabalho de conclusão de curso de Licenciatura em Artes Visuais. 


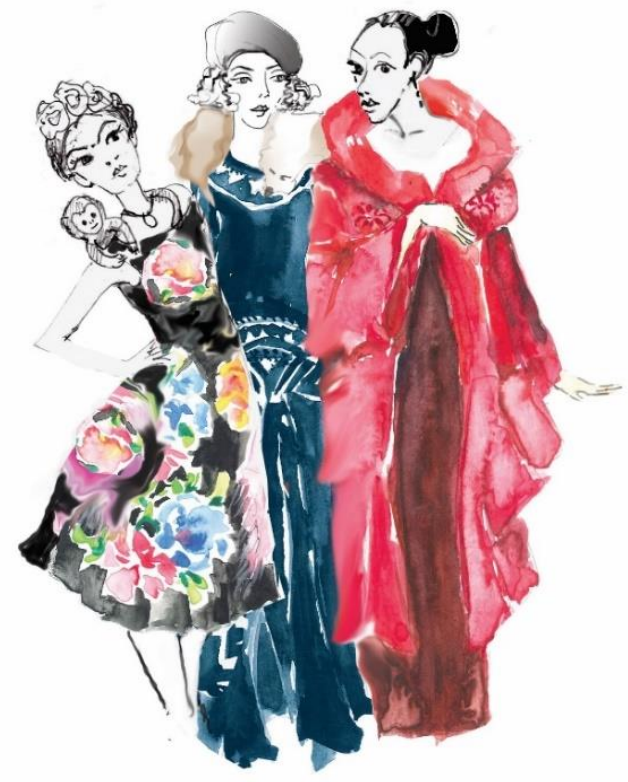

Figura 4 -Pesquisa sobre Arte e Moda, 2017/2018. Fonte: Autoras.

Temos observado como as artistas contemporâneas revisitam práticas tradicionais para ensejar reflexões originais, como o resgate do bordado e do crochê, modalidades depreciadas por sua "essencial feminilidade", fazer artesanal e privado, que elas alçam para o espaço dos museus, galerias de arte ou intervenções no espaço público, em escala monumental. A intenção é política e artística, busca ativar percepções sobre o trivial, propondo viradas simbólicas para construir novos significados e vencer preconceitos.

Compartilhando dos mesmos propósitos temos promovido rodas de bordado, costura, tricô e crochê. São atividades que nos permitem "estar junto" com os grupos mais diversos: crianças e jovens estudantes, artistas, professoras, mulheres artesãs e senhoras idosas. As experiências têm mobilizado a nós todas em ações de colaboração e partilha. É na roda que as histórias se revelam, memórias e imaginários se materializam nos artefatos, nos pequenos corações de feltro e nas "bonecas feias para mulheres bonitas", conforme propõe Clau Paranhos, artista voluntária do Projeto, nos convidando a seremos parte da sua pesquisa na linha de processos criativos e poéticas do cotidiano.

Mulheres que tecem e que bordam, que cultivam flores e constroem minijardins, ou um jardim inteiro, revitalizando terrenos abandonados, como fez Seli Maurício. A Tia Seli dos fantoches, como é conhecida em Pelotas, a artista, bonequeira e ativista, entre tantos outros fazeres que desempenha, integra nossa coleção de livros infanto-juvenis sobre as artistas do sul. Essa pesquisa, em desenvolvimento sob nossa coordenação, busca o reconhecimento das artistas de nossa região junto ao público escolar; por isso investimos na 
produção de livros ilustrados que enfatizam os processos criativos e lúdicos dessas artistas como proposição pedagógica (Figura 5).

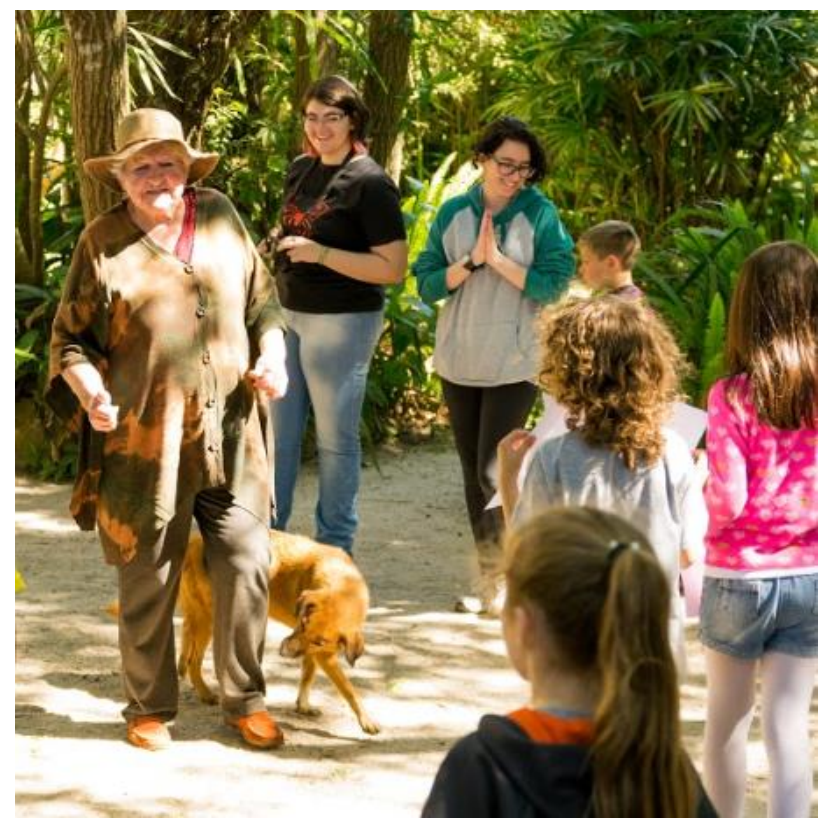

Figura 5 -Encontro com Seli Maurício, atividade da pesquisa 2017/2018. Fonte: Autoras

Mulheres artistas, que educam, pensam, escrevem, filosofam precisam emergir do obscurantismo que lhes é tradicionalmente imposto. As trajetórias estudadas são exemplos reveladores da dimensão humana e dos investimentos e enfrentamentos que essas protagonistas equacionaram para desconstruir cânones e formular novas teorias, ensejarem outros modos de ver e nos ver, mais plurais e inclusivos.

\section{Considerações Finais}

As ações de ensino e de capacitação promovidas pelo Projeto Arte na Escola buscam ultrapassar a noção de educação como mera conquista de saberes, nossa pretensão e compromisso é com o conhecimento sensível, capaz de promover ressignificações e originar posturas transformadoras. As equipes de trabalho se interessam em vivenciar os processos, atentando para as etapas constituintes, desde a instalação, concretização e avaliação dos resultados. As experiências são sistematizadas, apresentadas e divulgadas, se desdobrando em outras proposições pedagógicas e artísticas, cumprindo assim, um circuito ininterrupto, potente para alavancar o conhecimento da arte e do seu ensino. 
As ações contemplam o ensino, a pesquisa e a extensão como tríade unificada em prol de uma formação continuada, complementar e ampliada, capaz de apreender a diversidade, o trabalho colaborativo e se constituir em uma experiência que seja estética e cognitiva.

Em nossas avaliações e encontros com parceiros para projetar ajustes ou novas ações percebemos que não há receitas, ou soluções definitivas, ao contrário a atuação requer atualizações e continuidade, para efetivar vivências e práticas reflexivas, segundo um processo que demanda esforço e integração de todos os envolvidos.

Os grupos de estudo e pesquisa se caracterizam por reunirem integrantes em diferentes níveis de formação e atuação, acionando trocas e proporcionando qualificação profissional, enriquecimento estético e consciência cidadã. Temos observado o quanto as estratégias têm se revelado acertadas, seja por se instaurarem no espaço da escola, seja por provocarem os parceiros a trazerem suas necessidades, sacudindo concepções e promovendo atualizações e engajamentos político-pedagógicos.

A abertura para contemplar temas instigantes e o hibridismo nos modos de atuar, constitui um desafio, nos faz enfrentar diferenças, rever posições e reinventar outras relações com o mundo. Enfrentar a problemática significa adotar outros modos de pensar, menos restritivos e mais inclusivos, fundamentados no princípio da coletividade e no respeito aos direitos humanos. Para dar conta dos processos temos buscado metodologias emergentes, que desenvolvem narrativas, dispositivos e artefatos inovadores. Essa fluidez das dinâmicas vence obstáculos e tem contribuído para a inserção de egressos e professores atuantes na rede educacional da cidade e região, em nossos cursos de pós-graduação. $\mathrm{O}$ impacto positivo pode ser dimensionado pela efetiva capacitação que o Projeto viabiliza.

\section{Referências}

BARBOSA, Ana Mae (Org.). Inquietações e mudanças no ensino da Arte. São Paulo: Cortez, 2003.

MARTINS, Mirian Celeste; SCHULTZ, Ana Maria; EGAS, Olga (Orgs.). Mediando Contatos com Arte e Cultura. São Paulo: Ed. UNESP, 2007.

MARTINS, Raymundo; TOURINHO, Irene(Orgs.). Culturas das Imagens: desafios para a arte e para a educação. Santa Maria: Ed. UFSM, 2012.

DUARTE Jr., João Francisco. O sentido dos sentidos: a educação (do) sensível. 3. ed. Curitiba: Criar, 2004.

PERROT, Michelle. Minha história das mulheres. São Paulo: Contexto, 2017. 